\title{
Unique Structural Properties of the Mg-Al Hydrotalcite Solid Base Catalyst: An In Situ Study Using Mg and Al K-Edge XAFS during Calcination and Rehydration**
}

\author{
Jeroen A. van Bokhoven,* Jules C. A. A. Roelofs, Krijn P. de Jong, \\ and Diek C. Koningsberger ${ }^{[a]}$
}

\begin{abstract}
The changes in the layered structure of $\mathrm{Mg}-\mathrm{Al}$ hydrotalcite $(\mathrm{Mg} /$ $\mathrm{Al}=2$ ) during heat treatment have been investigated by using in situ XAFS simultaneously at the $\mathrm{Mg}$ and $\mathrm{Al}$ K-edges. The development of unique in situ instrumentation allowed the coordination environments at both the $\mathrm{Mg}$ and $\mathrm{Al}$ centers to be monitored as a function of the temperature and heat treatment. The results of this study show that the hydrotalcite structure is highly flexible, and should lead to the further development of hydrotalcites as new solid basic catalysts. Moreover, the $\mathrm{Mg}$ and $\mathrm{Al}$ cations in the cation layers show different behavior as a function of temperature. The coordination of some octahe-
\end{abstract}

dral $\mathrm{Al}$ ions decreases already at a temperature of $425 \mathrm{~K}$, whereas the coordination about $\mathrm{Mg}$ does not show any modification at this temperature. However, hydrotalcite treated at $425 \mathrm{~K}$, followed by cooling down to room temperature resulted in a complete reversal to the original octahedral $\mathrm{Al}$ coordination. It is proposed that $\mathrm{Al}-\mathrm{OH}$ bond breakage occurs at $\approx 425 \mathrm{~K}$, without the evolution of $\mathrm{H}_{2} \mathrm{O}$. This bond is restored after cooling to room temperature. The actual dehydroxylation of hydrotalcite

Keywords: EXAFS spectroscopy heterogeneous catalysis - hydrotalcite - solid bases commences between 425 and $475 \mathrm{~K}$, as indicated by a change in coordination of both the $\mathrm{Mg}$ and $\mathrm{Al}$ centers. This is accompanied by the evolution of $\mathrm{H}_{2} \mathrm{O}$ molecules and the changes are hence irreversible without the presence of excess water. Heat treatment at $725 \mathrm{~K}$ leads to the development of an $\mathrm{MgO}$ like phase (octahedral $\mathrm{Mg}$ ) and a mixed octahedral/tetrahedral Al phase. A subsequent rehydration at room temperature entirely restores the original coordination about the $\mathrm{Al}$ and $\mathrm{Mg}$ centers of hydrotalcite to a distance of $15 \AA$, to which XAFS spectroscopy is sensitive.

\section{Introduction}

Hydrotalcites (HTs) and structures derived therefrom have many applications that are related to their structural properties. ${ }^{[1]}$ Recently, modified HTs have proven to be active in the coupling of various ketones and aldehydes in base-catalyzed aldol condensation reactions, ${ }^{[2,3]}$ such as the condensation of citral and acetone to yield pseudoionone, which is an industrially important intermediary for the production of vitamin A. Usage of a solid base catalyst instead of the currently applied homogeneous alkaline bases makes reuse of the catalyst possible, leading to a reduction of waste streams. Furthermore, modified HTs display high activity already at

[a] Dr. J. A. van Bokhoven, J. C. A. A. Roelofs,

Prof. K. P. de Jong, Prof. D. C. Koningsberger

Debye Institute, Department of Inorganic Chemistry and Catalysis Utrecht University

Sorbonnelaan 16, 3508 TB Utrecht (The Netherlands)

Fax: $(+31) 302536763$

E-mail: j.a.vanbokhoven@chem.uu.nl

[**] XAFS $=\mathrm{X}$-ray absorption fine structure. low temperatures. These properties make HT-like compounds promising catalysts for commercial use.

The structure and the related activity of HT-like compounds are strongly related to the applied heat treatment. ${ }^{[3,4]}$ A calcination step at high temperature $(723-773 \mathrm{~K})$ followed by a rehydration step at room temperature yields a highly active catalyst for the catalytic reactions mentioned above. An understanding of the processes leading to an active catalyst, demands detailed knowledge of the structural changes in HT during heat treatment.

Hydrotalcite, $\left[\mathrm{Mg}_{6} \mathrm{Al}_{2}(\mathrm{OH})_{16}\right]\left(\mathrm{CO}_{3}\right) \cdot 4 \mathrm{H}_{2} \mathrm{O}$, is a layered double hydroxide (LDH). LDH structures are related to that of brucite, $\mathrm{Mg}(\mathrm{OH})_{2}$, in which the $\mathrm{Mg}$ cations occupy the centers of hydroxy octahedra. These octahedra are joined along their edges, forming a layered structure, composing hexagonal platelets. ${ }^{[1]}$ In hydrotalcite some of the $\mathrm{Mg}^{2+}$ ions are replaced by $\mathrm{Al}^{3+}$ ions, inducing a net positive charge in the cation layers. Charge-balancing anions (usually $\mathrm{CO}_{3}{ }^{2-}$ ) and water molecules are present in the interlayers.

X-ray diffraction (XRD), ${ }^{27} \mathrm{Al}$ MAS NMR, IR, thermal gravimetric analysis (TGA), and $\mathrm{CO}_{2}$ temperature program- 
med desorption (TPD) are often used techniques to determine the structure of HTs. It is well documented that for HTs, physisorbed and interstitial water is removed at temperatures above approximately $325 \mathrm{~K}$ and $460 \mathrm{~K}$, respectively. At higher temperatures the HT undergoes dehydroxylation and decarboxylation, giving rise to $\mathrm{H}_{2} \mathrm{O}$ and $\mathrm{CO}_{2}$ evolution. XRD indicates the formation of an $\mathrm{MgO}$-like phase at temperatures above $725 \mathrm{~K},{ }^{[5]}$ and in addition, at those temperatures, an amorphous $\mathrm{Al}_{2} \mathrm{O}_{3}$ phase is formed. Above about $1100 \mathrm{~K}$ the normal spinel $\mathrm{MgAl}_{2} \mathrm{O}_{4}$ appears. ${ }^{[6]}$

${ }^{27} \mathrm{Al}$ MAS NMR spectroscopy ${ }^{[7,8]}$ shows that the coordination of $\mathrm{Al}$ is lowered from octahedral to tetrahedral after calcination above $500 \mathrm{~K}$. This process already commences at relative low temperatures. Rehydration of the calcined product at room temperature results in a restoration of the original structure, which is both shown with XRD and ${ }^{27} \mathrm{Al}$ MAS NMR spectroscopy. XRD indicates a return of the platelike structure and the NMR spectrum indicates the reappearance of octahedrally coordinated $\mathrm{Al}$ centers. This socalled memory effect is lost after calcination above $773 \mathrm{~K}$, due to the formation of the stable spinel $\mathrm{MgAl}_{2} \mathrm{O}_{4} \cdot{ }^{[1]} \mathrm{A}$ calcination-rehydration cycle yields a modified HT with mainly $\mathrm{OH}^{-}$ions as charge-balancing anions. Repeated calcinationrehydration cycles result in the segregation of $\mathrm{Al}$ from the cation layer and in the formation of spinel $\mathrm{MgAl}_{2} \mathrm{O}_{4} \cdot{ }^{[9]}$ Until now, little is known about the changes in the coordination at the $\mathrm{Mg}$ centers during heat treatment and subsequent rehydration. One ${ }^{25} \mathrm{Mg}$ MAS NMR study on hydrotalcite calcined to various temperatures shows the formation of a poorly crystalline $\mathrm{MgO}$ phase after calcination above $675 \mathrm{~K} .^{[7]}$

To be able to understand and therefore to optimize the activation process, in situ characterization is a necessity. Recent instrumental development ${ }^{[10,11]}$ has enabled in situ measurements by X-ray absorption fine structure spectroscopy (XAFS) at the $\mathrm{Mg}$ and $\mathrm{AlK}$-edges. XAFS at the $\mathrm{Al}$ and $\mathrm{MgK}$-edges provides electronic and geometric information about these elements. The different coordinations at $\mathrm{Mg}$ and $\mathrm{Al}$ can clearly be distinguished by the appearance of characteristic features in the near-edge spectra. ${ }^{[12]}$ HT-like compounds have been studied by using XAFS spectroscopy, however, application of in situ studies was until now restricted to heavy elements. ${ }^{[13]}$

In this study, structural information of both $\mathrm{Mg}$ and $\mathrm{Al}$ is obtained by measuring the $\mathrm{Mg}$ and $\mathrm{AlK}$-edges under in situ (at elevated temperature) and ex situ (at room temperature after previous treatment in the laboratory) conditions. It will be shown that large differences exist between the results obtained by in situ and ex situ studies of the samples. Changes in coordination due to calcination and rehydration of hydrotalcite with $\mathrm{Mg} / \mathrm{Al}=2$ will be discussed. Unique information can be obtained since the coordinations of the $\mathrm{Al}$ and $\mathrm{Mg}$ centers are determined in the same in situ experiment.

\section{Results}

\section{Mg reference compounds}

Figure 1 shows the $\mathrm{Mg} \mathrm{K}$-edge spectra of the reference materials having different $\mathrm{Mg}$ coordinations. The spectrum of $\mathrm{MgAl}_{2} \mathrm{O}_{4}$ was digitized from reference [14]. The position of

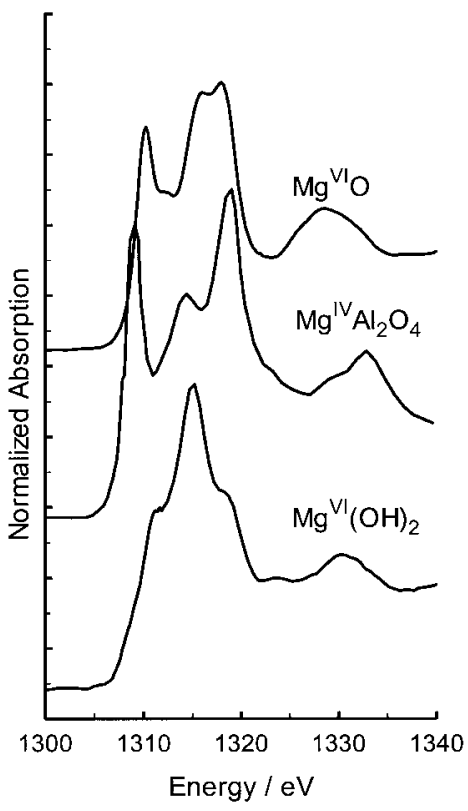

Figure 1. $\mathrm{Mg} \mathrm{K}$-edge spectra of reference compounds having tetrahedrally and octahedrally coordinated $\mathrm{Mg}$ centers.

the absorption edge in the spectrum of tetrahedral $\mathrm{Mg}$ in $\mathrm{MgAl}_{2} \mathrm{O}_{4}$ is lower in energy than the absorption edge in the spectrum of octahedral $\mathrm{Mg}$. In the spectrum of $\mathrm{Mg}(\mathrm{OH})_{2}$, a slowly rising edge is visible. However, the first maximum appears at approximately the same energy as the first maximum in the spectrum of $\mathrm{MgO}$. These reference compounds show Mg K-edge spectra that are very similar to earlier reported data. ${ }^{[14]}$

\section{Al reference compounds}

The Al K-edge spectra of reference compounds containing tetrahedral and octahedral $\mathrm{Al}$, respectively, are presented in Figures $2 \mathrm{a}$ and $2 \mathrm{~b}$, respectively. These spectra and the

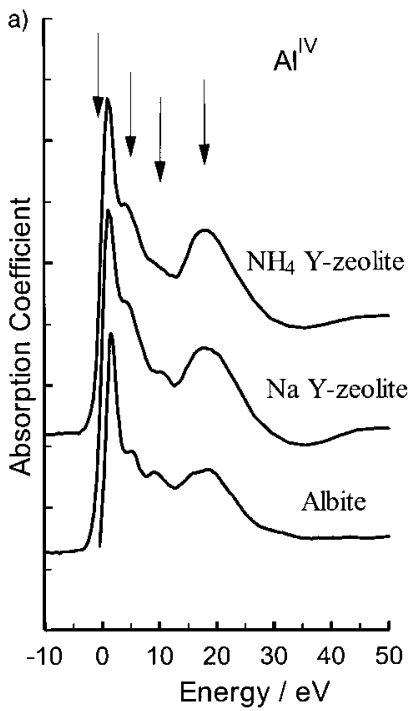

b)

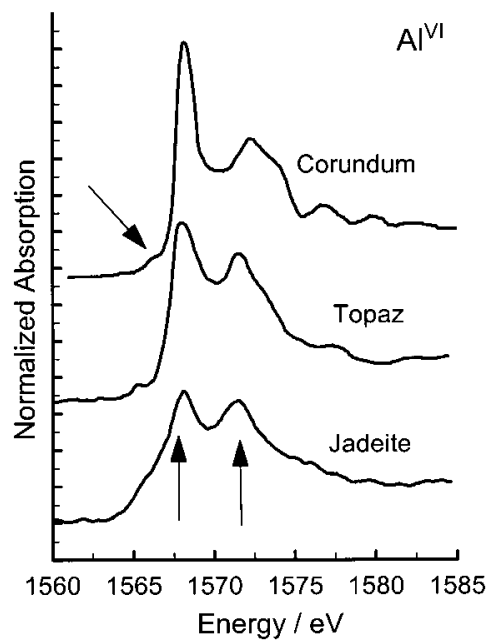

Figure 2. Al K-edge spectra of reference compounds having tetrahedrally (a) and octahedrally (b) coordinated aluminum centers. 
relationship between the characteristic features (indicated by arrows) in the spectra and the structure of the samples have been discussed extensively elsewhere. ${ }^{[12,15,16,17,18]}$ It was concluded that the characteristic features in the near-edge spectra are indicative of different $\mathrm{Al}$ coordinations in the compounds. ${ }^{[12]}$ Criteria that can be used, are: 1 ) energy position of the edge, 2) intensity in the near-edge region, 3) shape of the whiteline, and 4) peaks at specific energy, including pre-edges. These different characteristic features are evident in Figures $2 \mathrm{a}$ and $2 \mathrm{~b}$. In general, an octahedral compound shows two resonances above the absorption edge at 1568 and $1572 \mathrm{eV}$, whereas a tetrahedral compound shows a single sharp rising edge at $1566 \mathrm{eV}$. Moreover, the near-edge in a spectrum of an octahedral compound has higher intensity than the near-edge for a tetrahedral compound. A broad peak at $20 \mathrm{eV}$ above the absorption edge is visible in $\mathrm{Al} \mathrm{K}$-edge spectra of tetrahedral compounds. It is emphasized here that the near-edge region $(0-15 \mathrm{eV}$ above the edge) in the $\mathrm{Al} \mathrm{K}$-edge spectra is determined by long-range multiple scattering. ${ }^{[19]}$ Thus, the fine structure and peaks that appear in the spectra in this energy range are determined by ordering of the structure in the range $0-15 \AA$ around the absorber.

\section{As-synthesized hydrotalcite}

Figure 3 shows the $\mathrm{Mg}$ and $\mathrm{Al} \mathrm{K}$-edge near-edge spectra of the as-synthesized hydrotalcite (HTa.s.). The energy scales of these spectra are aligned on the first maximum in the spectra,

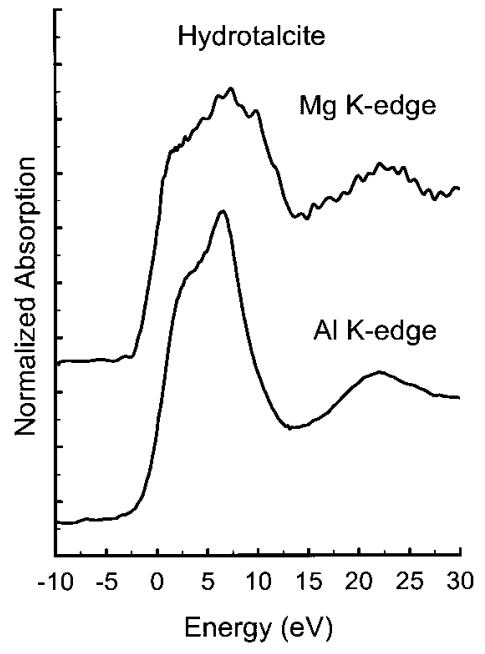

Figure 3. $\mathrm{Mg}$ and $\mathrm{Al} \mathrm{K}$-edge spectra of as-syntehsized hydrotalcite $(\mathrm{Mg} /$ $\mathrm{Al}=2: 1)$.

and are set to $0 \mathrm{eV}$. The spectrum taken at the $\mathrm{Mg} \mathrm{K}$-edge is shifted by $1308 \mathrm{eV}$, and that taken at the Al K-edge by $1565 \mathrm{eV}$.

The Al K-edge spectrum is characteristic of a spectrum of octahedrally coordinated Al centers: It shows a split whiteline with resonances at 1568 and $1572 \mathrm{eV}$, indicated by arrows in Figure $2 \mathrm{~b}$. The spectrum is identical to an $\mathrm{Al} \mathrm{K}$-edge spectrum of HT reported in the literature. ${ }^{[20]}$ No intensity at $1566 \mathrm{eV}$, characteristic of tetrahedral $\mathrm{Al}$ centers is found.
The Mg K-edge spectrum of HTa.s. is very similar to its Al K-edge spectrum, although the peaks are less distinct and broadened and a surplus in intensity at about $10 \mathrm{eV}$ above the absorption edge is visible. The spectrum is different from the spectrum of brucite $\mathrm{Mg}(\mathrm{OH})_{2}$ (Figure 1), indicating that $\mathrm{Mg}$ in HT has a somewhat different octahedral structure.

\section{Ex situ treated hydrotalcite}

Figure 4 shows the room temperature $\mathrm{Mg} \mathrm{K}$-edge spectra of the ex-situ treated hydrotalcite $\left(\mathrm{HTex}^{\prime} T^{\prime}\right.$; where ' $T$ ' $=$ maximum calcination temperature) samples. The spectrum of

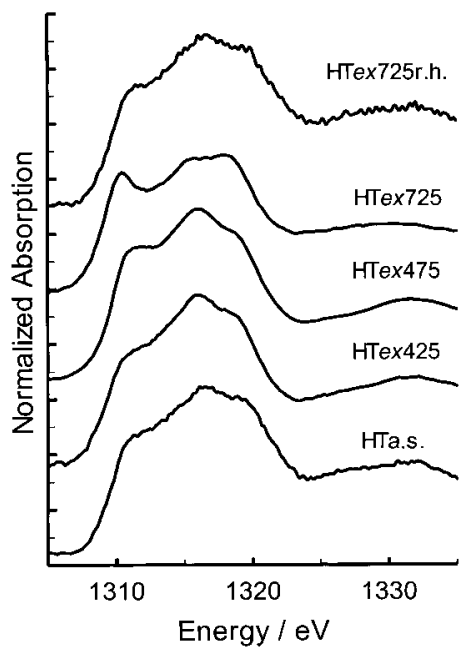

Figure 4. Mg K-edges of ex situ heat-treated hydrotalcite, showing a gradual change in the spectra after treatment above $475 \mathrm{~K}$. A restoration of the structure is visible for a rehydrated sample that had previously been heated to $725 \mathrm{~K}$ (HTex725r.h.).

HTex425, is identical to the spectrum of HTa.s. After heating the hydrotalcite above $475 \mathrm{~K}$, changes in the spectra appear: an increase in the intensity at about $1310 \mathrm{eV}$ is observed. The absorption edge of the spectrum of HTex725 is shifted to lower energy and a clear decrease in intensity in the range 5 to about $15 \mathrm{eV}$ above the edge is visible. Moreover, the peak at about $1330 \mathrm{eV}$ occurs at a different energy than samples that are treated at lower temperature, indicating a change in $\mathrm{Mg}$ coordination. The spectrum of HTex 725 resembles the spectrum of $\mathrm{MgO}$ (see Figure 1); however, the peaks are less distinct and less fine structure is visible in the spectrum of HTex725. The spectrum of the calcined and subsequent rehydrated HT (HTex725r.h.; Figure 4) is identical to the spectrum of the starting material, HTa.s., showing a complete and quantitative reversal of $\mathrm{Mg}$ coordination after rehydration.

The Al K-edge spectra of the HTex' $\mathrm{T}^{\prime}$ samples are given in Figures $5 \mathrm{a}$ and $5 \mathrm{~b}$. The spectrum of HTex 425 does not differ from the spectrum of HTa.s. A detailed comparison of the spectrum of HTex 475 and HTex 425 is given in Figure $5 \mathrm{~b}$. The spectrum of HTex 475 shows a decrease in intensity of the octahedral peaks and an increase in intensity is visible at $1566 \mathrm{eV}$, showing a decrease in octahedral content, while tetrahedral $\mathrm{Al}$ centers appear. This is continued progressively at higher temperatures, as clearly visible in the spectrum of HTex725. The difference between the spectrum of HTa.s. and HTex725 is highlighted in Figure 6 by subtracting the spec- 

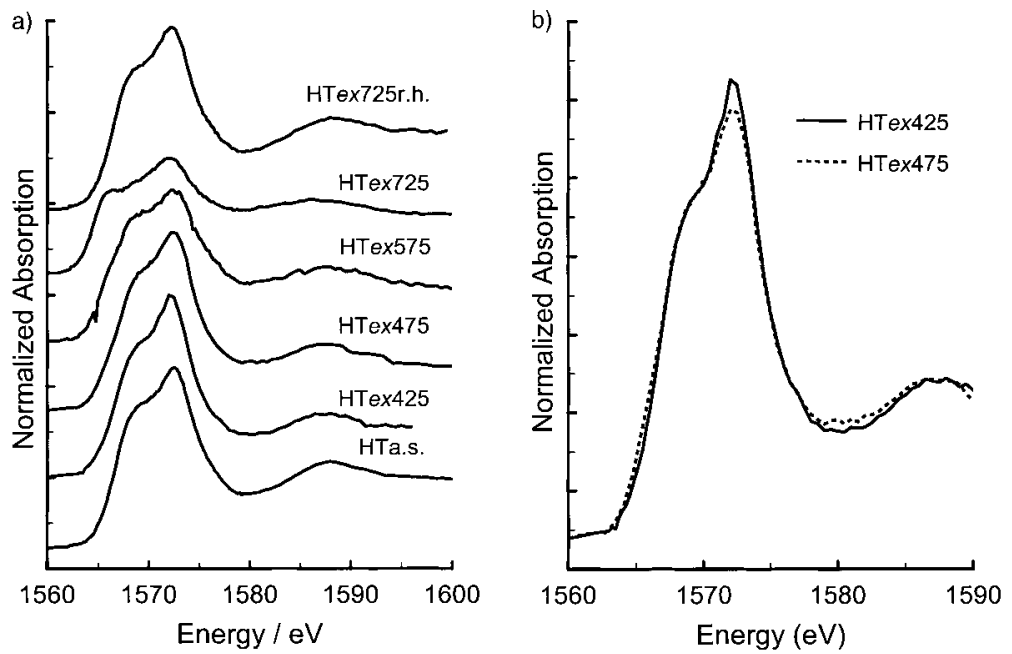

Figure 5. a) Al K-edges of ex situ heat-treated hydrotalcite, showing a gradual change in the spectra after treatment above $475 \mathrm{~K}$. b) Al K-edge of HTex425 and HTex475.
' $T$ ' is the temperature at which the sample was measured). In the $\mathrm{Mg}$ K-edge spectra, no changes can be observed between HTa.s. and HT425 within the noise-level. An increase in intensity just on the absorption edge is visible in the spectra recorded for HT475.

Figure 8 shows the corresponding $\mathrm{Al} \mathrm{K}$-edge spectra which clearly show the differences between the spectrum for HT425 and that for HTa.s. The changes consist of a decrease in intensity of the two peaks at 1568 and $1572 \mathrm{eV}$, and an edge shift towards lower energy.

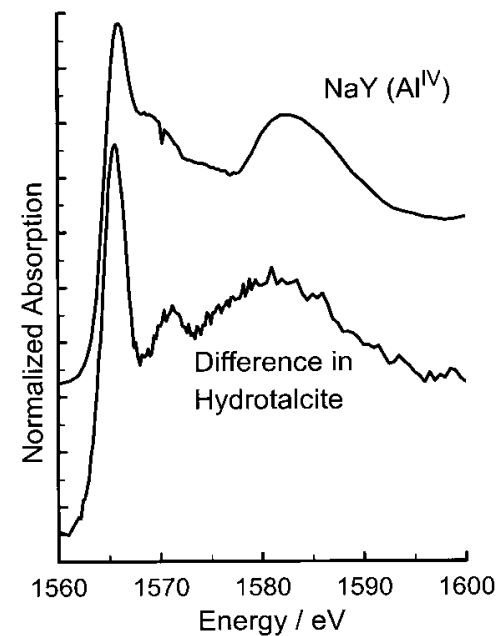

Figure 6. Contribution of tetrahedral Al sites isolated from HTex725 compared to a tetrahedral $\mathrm{Al}$ reference compound ( $\mathrm{NaY}$ zeolite).

trum of HTa.s. from that of HTex725 while applying a normalization factor. In this manner the octahedral contribution to the spectrum of HTex725 can be removed leaving the contribution of the changed $\mathrm{Al}$ coordination in the spectrum. The normalization factor is varied until the difference spectrum did not contain any non-realistic negative contributions below the absorption edge. ${ }^{[12]}$ This difference spectrum is compared to a reference compound of tetrahedral $\mathrm{Al}$ (such as zeolite $\left.\mathrm{NaY}^{[12]}\right)$. This spectrum reveals all the characteristic features of tetrahedral Al centers: A sharp absorption edge at $1566 \mathrm{eV}$, two features at 5-10 eV above the absorption edge, and a broad peak at about $20 \mathrm{eV}$. The spectra differ at 3-7 eV above the absorption edge, which may be due to a somewhat different octahedral coordination in the calcined HT, in comparison to the parent hydrotalcite, HTa.s.

\section{High temperature treated hydrotalcite}

Figure 7 shows the $\mathrm{Mg} \mathrm{K}$-edge spectra of hydrotalcite that are measured during treatment at high temperature $\mathrm{HT}^{\prime} T^{\prime}$ (where

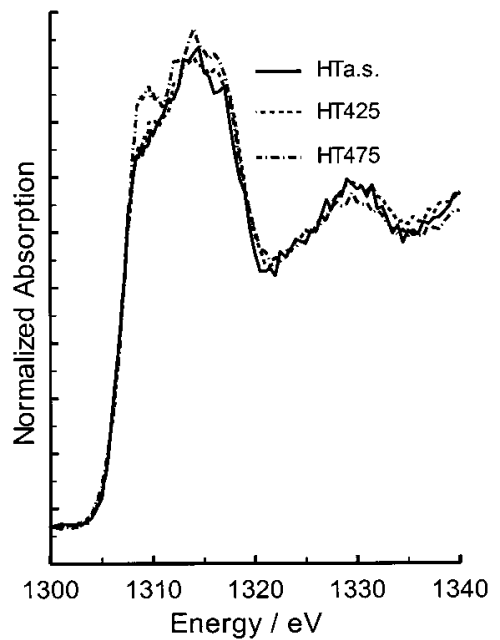

Figure 7. In situ measured $\mathrm{Mg} \mathrm{K}$-edge spectra of hydrotalcite indicating a change in $\mathrm{Mg}$ coordination at temperatures above $475 \mathrm{~K}$.

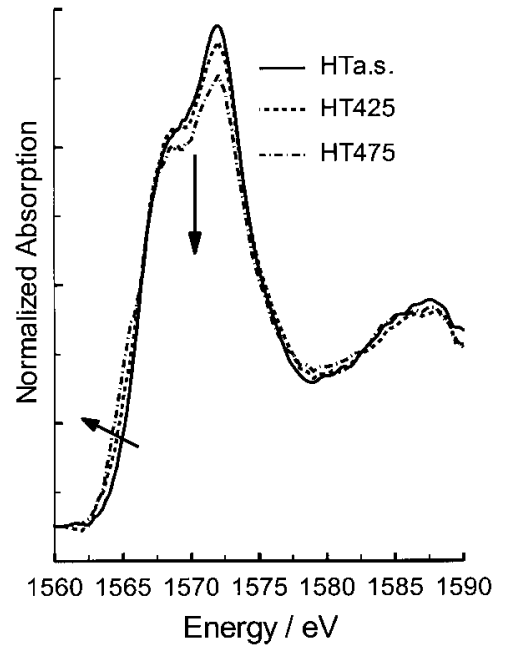

Figure 8. In situ measured Al K-edge spectra of hydrotalcite showing the appearance of less coordinated $\mathrm{Al}$ sites already at $425 \mathrm{~K}$. 
Moreover, a small increase in intensity at about $20 \mathrm{eV}$ above the absorption edge appears, which is indicative of an increase in the tetrahedral $\mathrm{Al}$ content. ${ }^{[12]}$ The differences in the spectrum taken at $475 \mathrm{~K}$ are more distinct.

\section{EXAFS analysis}

The Fourier transforms after background subtraction and normalization of the Al K-edge spectra of HTa.s. and HTex725 are given in Figure 9. Both the magnitude and the

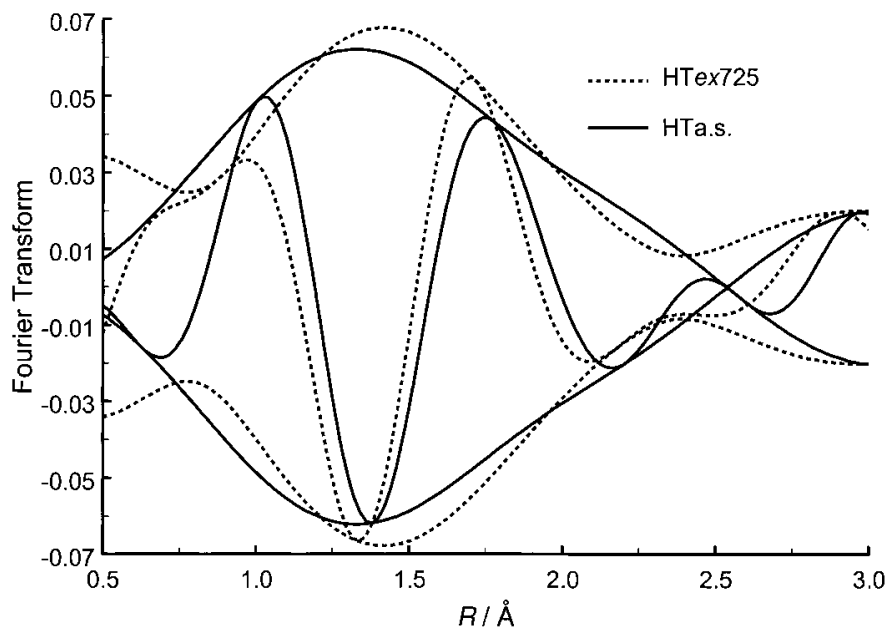

Figure 9. Fourier transform $\left(k^{1}, \Delta k=2.7-8 \AA\right)$ of the Al K-edge EXAFS of HTex725 and HTa.s. indicating differences in $\mathrm{Al}-\mathrm{O}$ bond length and in coordination number by differences in node positions of the imaginary part and in absolute intensity.

node positions of the imaginary part are different, indicating differences in $\mathrm{Al}-\mathrm{O}$ bond length and coordination number between HTa.s. and HTex725. $R$ space fits of the spectra are given in Figure 10 (HTa.s.) and 11 (HTex725). The fit param-

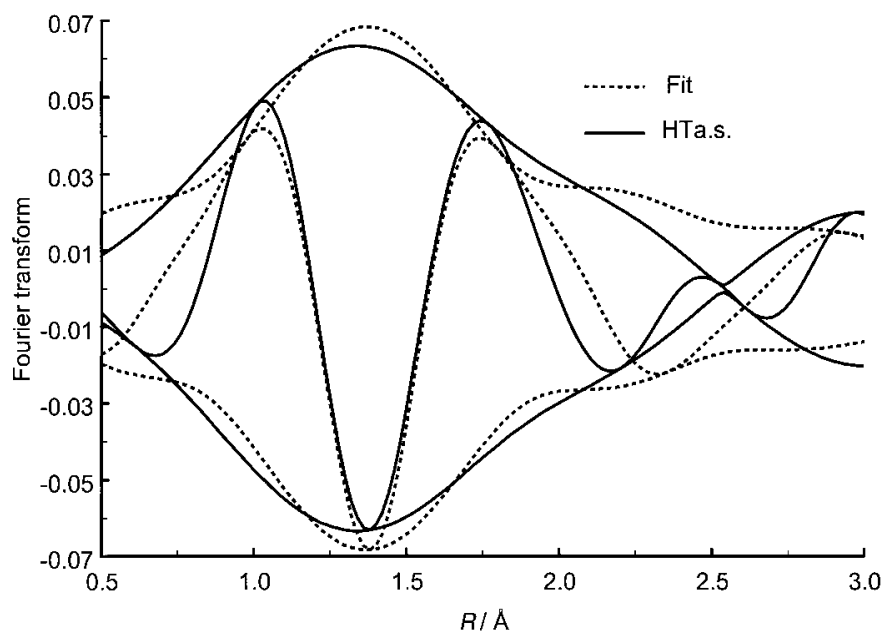

Figure 10. Fourier transform $\left(k^{1}, \Delta k=2.7-8 \AA\right)$ of the Al K-edge EXAFS of HTa.s. and the best fit obtained.

eters are given in Table 1. The spectrum of HTa.s. was fitted using one shell of oxygen neighbors, and a reasonable agreement of intensity and especially node position is
Table 1. $\mathrm{Al}-\mathrm{O}$ fitted coordination parameters. ${ }^{[\mathrm{a}]}$

\begin{tabular}{llccr}
\hline & \multicolumn{4}{c}{ Parameters } \\
& $N$ & $\Delta \sigma^{2}[\AA]$ & $R[\AA]$ & $\Delta E_{0}[\mathrm{eV}]$ \\
\hline HTa.s. & 6 & 0.0002 & 1.82 & 3.17 \\
HTex450 oct & 4.9 & -0.064 & 1.86 & -5.49 \\
tet & 0.7 & 0.01 & 1.56 & -8.55 \\
\hline
\end{tabular}

[a] Fitted in $R$ space, $1<R<2,2.7<k<8, k^{1}$-weighted.

obtained. An $\mathrm{Al}-\mathrm{O}$ bond lengths of 1.83 and $1.86 \AA$ in $\mathrm{HT}$ are normal for octahedrally coordinated $\mathrm{Al}$ centers (compare the $\mathrm{Al}-\mathrm{O}$ bond lengths in corund which has three $\mathrm{Al}-\mathrm{O}_{\mathrm{a}}$ bonds of $1.86 \AA$ and three $\mathrm{Al}-\mathrm{O}_{\mathrm{b}}$ bonds of $1.97 \AA^{[21]}$ ).

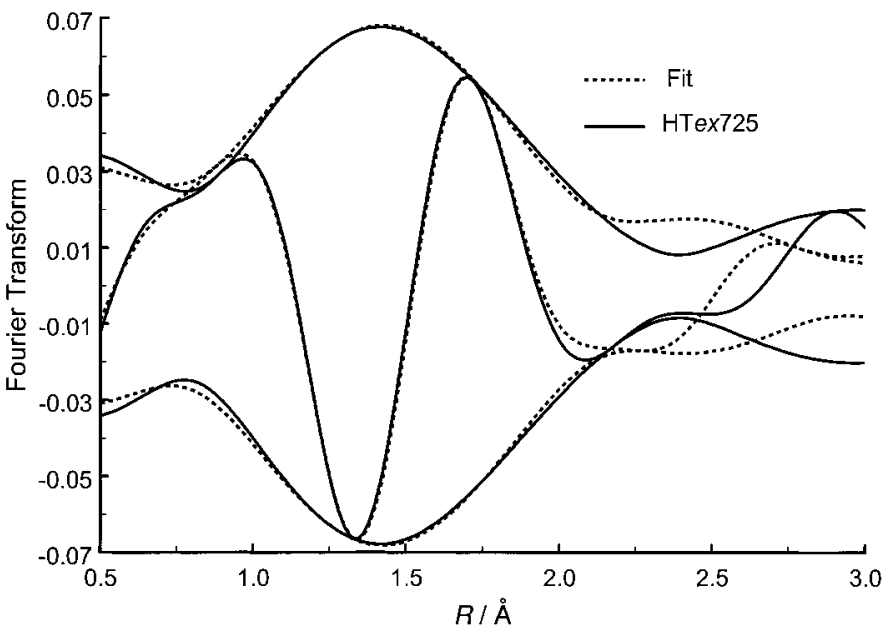

Figure 11. Fourier transform $\left(k^{1}, \Delta k=2.7-8 \AA\right)$ of the Al K-edge EXAFS of HTex 725 and the best fit obtained.

The near-edge spectrum of HTex725 (Figure 5a) indicated the presence of both tetrahedrally and octahedrally coordinated $\mathrm{Al}$ centers. Therefore, a two-shell fit was performed on the normalized EXAFS of HTex 725 , one comprising the tetrahedrally coordinated Al centers and one the octahedrally coordinated $\mathrm{Al}$ centers. The resulting fit was within the noiselevel (Figure 11). In order to verify the effect of fitting a second shell to the spectrum of HTa.s., a two-shell fit was performed also for this spectrum; however, this did not lead to a better fit.

The coordination numbers $(N)$ given in Table 1 are fractional, since in XAS spectroscopy a sum of all contributing atoms is measured. The shell with the shorter $\mathrm{Al}-\mathrm{O}$ bond length represents the tetrahedrally coordinated content, and the longer bond length denotes the octahedrally coordinated content.

\section{Discussion}

\section{$\mathrm{Mg}$ and Al coordinations in the HT structure}

Figure 3 shows that in as-synthesized hydrotalcite, the edges in the respective $\mathrm{Al}$ and $\mathrm{Mg} \mathrm{K}$-edge spectra have similar characteristics, which is expected for two neighboring elements in the Periodic Table occupying identical cation positions. Both spectra show two peaks just above the 
absorption edge that are more pronounced in the spectrum recorded at the $\mathrm{Al} \mathrm{K}$-edge. These peaks are broader in the $\mathrm{Mg}$ spectrum, which also has significant intensity at about $10 \mathrm{eV}$ above the edge. In the HT structure, $\mathrm{Al}$ always has six $\mathrm{Mg}$ atoms at next-nearest-neighbor positions (connected through $\mathrm{OH}$ groups), whereas $\mathrm{Mg}$ has both $\mathrm{Al}$ and $\mathrm{Mg}$ at these positions. ${ }^{[1]}$ This more variable coordination around the $\mathrm{Mg}$ cations could result in less distinct peaks in the near-edge in $\mathrm{Mg}$ K-edge spectra. The broadening of the peaks in the $\mathrm{Mg}$ spectra could indicate that $\mathrm{Mg}$ has-on average-a more distorted environment than $\mathrm{Al}$ in terms of its first few coordination spheres within one cation layer: An X-ray absorption spectrum is an average of all the atoms contained in the sample. The near-edge in the spectra is determined by long-range scattering, and it is thus sensitive to ordering up to about $15 \AA$ around the absorber (being either $\mathrm{Mg}$ or $\mathrm{Al}$ ). ${ }^{[19]}$

The broad peak at about $25 \mathrm{eV}$ above the absorption edge is visible at both edges, which again is evidence for $\mathrm{Mg}$ and $\mathrm{Al}$ occupying identical cation positions. The Mg K-edge spectrum of brucite $\left(\mathrm{Mg}^{\mathrm{VI}}(\mathrm{OH})_{2}\right.$; Figure 1) shows sharper resonances and more fine structure than the spectrum of HTa.s. This is also evidence of less structured $\mathrm{Mg}$ coordination in HT than in brucite in the $0-15 \AA$ range around the $\mathrm{Mg}$ atoms in both these structures. This local disorder is also observed in the XRD pattern of HT. In XRD spectra of HT, the in-plane reflections are relatively broad ${ }^{[1,2,3]}$ showing disorder at a somewhat longer range.

\section{Changing Mg and Al coordinations as a function of temper- ature}

HTex' $\boldsymbol{T}^{\prime}$ samples: The $\mathrm{Al}$ and $\mathrm{Mg}$ coordinations change strongly as a function of the temperature of calcination. The edge in the Mg K-edge spectra (Figure 4) shifts to somewhat lower energy, and the intensity in the near-edge decreases. The Mg K-edge spectrum of HT calcined at $725 \mathrm{~K}$, strongly resembles the spectrum of $\mathrm{Mg}^{\mathrm{VI}} \mathrm{O}$ (Figure 1), indicating an $\mathrm{MgO}$-like phase is formed during calcination at $725 \mathrm{~K}$. In this structure the $\mathrm{Mg}$ center becomes octahedrally coordinated as in the rock salt structure. The rehydration at room temperature completely restores the original spectrum (Figure 4), indicating the $\mathrm{Mg}$ coordination is identical to that of $\mathrm{Mg}$ in assynthesized HT, HTa.s., that is distorted octahedal.

The Al K-edge spectra show a progressive decrease in intensity of the characteristic peaks for octahedral coordination at 1568 and $1572 \mathrm{eV}$, and an increase in intensity at $1566 \mathrm{eV}$ (Figures $5 \mathrm{a}$ and $5 \mathrm{~b}$ ) after calcination above $475 \mathrm{~K}$. Figure 6 shows the difference spectrum obtained from the subtracting the spectrum of HTa.s. from that of HTex725. This difference spectrum shows large similarities with the spectrum of $\mathrm{NaY}$, which can be considered as a typical spectrum of tetrahedrally coordinated Al. This provides direct evidence for the presence of tetrahedrally coordinated $\mathrm{Al}$ centers after calcination of HT. The Al coordination can be quantitatively reversed to its original coordination after rehydration (HTex725r.h.). No indications exist of other modes of coordination ( $\mathrm{Mg}$ or $\mathrm{Al})$ in the rehydrated HT (HTex725r.h.) other than those already present in the as-synthesized HT.
$\mathbf{H T}^{\prime} \boldsymbol{T}^{\prime}$ samples: Figures 7 and 8 show the $\mathrm{Mg}$ and $\mathrm{Al} \mathrm{K}$-edge spectra, respectively, measured in situ at room temperature, 425 , and $475 \mathrm{~K}$. At $425 \mathrm{~K}$, the $\mathrm{Al}$ coordination already begins to change, which was not observed for the pretreated (at $425 \mathrm{~K}$ ) calcined sample (HTex425) measured at room temperature. The $\mathrm{Mg}$ coordinations in $\mathrm{HT}^{\prime} T^{\prime}$ samples start changing at a temperature of $475 \mathrm{~K}$, very similar to the case for HTex' $T^{\prime}$ samples. This is the temperature of the pretreated samples at which also the Al spectra showed changes (HTex475, Figures $5 \mathrm{a}$ and $5 \mathrm{~b})$. Apparently, the changes in $\mathrm{Al}$ coordination induced by calcination at $425 \mathrm{~K}$ (HT425) are fully reversed upon cooling down the sample to room temperature. Only when the $\mathrm{Mg}$ coordination is changed (which occurs above $475 \mathrm{~K}$ ), the changes in the $\mathrm{Al}$ coordination are no longer reversible. This information is only available through performing XAFS experiments during the heat treatment. The consequences of this observation are discussed in the next section.

\section{Discussion of the structure of HT}

Activation of hydrotalcite is performed by calcination up to $725 \mathrm{~K}$ and followed by a rehydration step. The chargebalancing $\mathrm{CO}_{3}^{2-}$ ions are (largely) replaced by $\mathrm{OH}^{-}$ions. After this calcination-rehydration cycle no new $\mathrm{Mg}$ and $\mathrm{Al}$ coordination modes are observed by $\mathrm{Mg}$ and $\mathrm{Al} \mathrm{K}$-edge $\mathrm{XAFS}$; the $\mathrm{Mg}$ and $\mathrm{Al}$ coordinations are completely restored to the original octahedral hydrotalcite structure. During heat treatment, however, the $\mathrm{Al}$ and $\mathrm{Mg}$ coordinations alter. The in situ and ex situ experiments show clear differences, indicating the importance of using a true in situ technique.

Although some controversy exists concerning the temperatures at which changes in the HT structure occur, there is a common concensus that first adsorbed and interstitial $\mathrm{H}_{2} \mathrm{O}$ is removed from the interlayer; second, dehydroxylation at the cation layers occurs, creating less coordinated $\mathrm{Al}$ centers. ${ }^{27} \mathrm{Al}$ MAS NMR spectroscopy recorded at elevated temperatures indicate that this process occurs already at temperatures above $375 \mathrm{~K} .{ }^{[7]}$ Here it is shown more specifically that the coordination of $\mathrm{Al}$ is lowered at a temperature of $425 \mathrm{~K}$. However, these changes are reversible after cooling down the sample to room temperature. As shown in Scheme 1 at $425 \mathrm{~K}$,

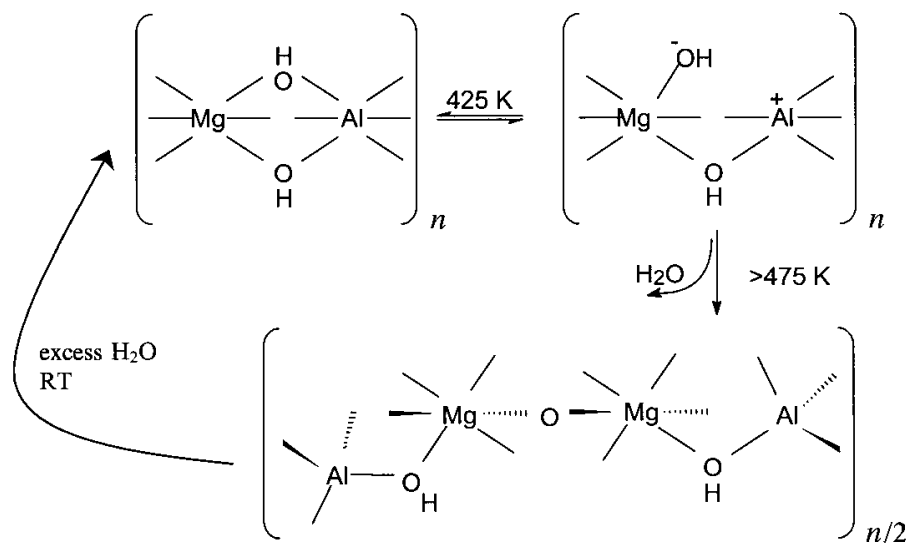

Scheme 1. Processes occurring during heat treatment of hydrotalcite. 
a few $\mathrm{Al}-\mathrm{OH}$ bonds are broken, which lowers the $\mathrm{Al}$ coordination. However, this occurs without dehydroxylation at the cation layers. Most likely these are $\mathrm{Al}-\mathrm{OH}-\mathrm{Mg}$ groups that are positioned near the edges of the cation layers or in the top or bottom layer in the stacked cation layer arrangement.

The processes proposed in Scheme 1 are a working hypothesis. The structure as drawn in Scheme 1 at a temperature of $475 \mathrm{~K}$ could be stabilized by anions and water molecules in the interlayer through a delocalization of charge. It has been proposed ${ }^{[22]}$ that diffusion of protons and the reaction with hydroxyl ions to form water are the initial steps in the thermal decomposition of gibbsite, whose structure resembles that of hydrotalcite. Gibbsite also has a layered structure of octahedrally coordinated aluminum hydroxides. In hydrotalcites, a proton of a nearby hydroxide could diffuse to an $\mathrm{Al}-\mathrm{OH}$ group at $475 \mathrm{~K}$, yielding a water molecule. This water molecule coordinates less strongly to the aluminum center, hence the aluminum coordination is lowered. The relatively low temperature prevents this water molecule from completely losing contact with the aluminum center, and the structural change is fully reversed after cooling down the sample to room temperature.

At temperatures above $475 \mathrm{~K}$, the actual dehydroxylation process commences and a change of both the $\mathrm{Mg}$ and $\mathrm{Al}$ coordination is expected, exactly as observed. These dehydroxylation processes are no longer reversible as indicated in Scheme 1 . At $475 \mathrm{~K}$, the $\mathrm{Mg}-\mathrm{OH}$ bonds start breaking and the coordination at the $\mathrm{Mg}$ centers is altered by the formation of new $\mathrm{Mg}-\mathrm{O}-\mathrm{Mg}$ bonds. This process is accompanied by the evolution of $\mathrm{H}_{2} \mathrm{O}$ from the sample. At this temperature, the formation of a rocksalt $\mathrm{MgO}$-like phase starts occurring $(\mathrm{Mg}$ has an octahedral coordination in $\mathrm{MgO}$ ). Once this phase has formed, the changes to the structure are no longer reversible after the sample has been cooled down. However, the addition of an excess of water (during rehydration at room temperature) fully reverses the changes in the coordinations, even after the hydrotalcite has been calcined to $725 \mathrm{~K}$. X-ray diffraction reveals a change in the 003 and 006 reflections at about $455 \mathrm{~K},{ }^{[3,6,23]}$ showing a decrease in interlayer distance. This was attributed to a loss of interstitial $\mathrm{H}_{2} \mathrm{O}$. However, as shown in this study, at $425 \mathrm{~K}$ the $\mathrm{Al}$ coordination is already changing, and at $475 \mathrm{~K}$ also the $\mathrm{Mg}$ coordination. Thus at $425 \mathrm{~K}$, some $\mathrm{Al}-\mathrm{OH}$ bond-breaking occurs, and above $475 \mathrm{~K}$, dehydroxylation is already occurring. It is therefore concluded that changes to the structure at these low temperatures take place in the interlayers as well as inside the $\mathrm{Mg}-\mathrm{Al}$ hydroxide layers, the latter probably near the external surface of the cation layers.

At higher temperatures decarboxylation occurs, which is accompanied by the formation of an $\mathrm{MgO}$ phase. It has been proposed that dehydroxylation first occurs within one layer, and that only after removal of carboxyl ions a dehydroxylation between two consecutive layers may occur. ${ }^{[24]}$ This last process is accompanied by a loss of the lamellar arrangement of the layers leading to drastic changes in the XRD pattern. The temperature at which this process occurs starts at $525 \mathrm{~K}$ and continues up to $800 \mathrm{~K}$. The structures formed after calcination at these temperatures still exhibit the so-called memory effect, ${ }^{[1]}$ although the restoration of the HT layered structure is much slower for the samples calcined at the higher temperatures. The decarboxylation results in an $\mathrm{MgO}$-like phase and a mixed tetrahedral-octahedral $\mathrm{Al}_{2} \mathrm{O}_{3}$ phase, which is confirmed in this study. The EXAFS of the HTex725 sample could be fitted taking two $\mathrm{Al}-\mathrm{O}$ shells into account (Table 1). This shows the presence of both tetrahedrally and octahedrally coordinated aluminum centers with a short and a long $\mathrm{Al}-\mathrm{O}$ bond length, respectively. However, a comparison of the Mg K-edge spectra of HTex725 (Figure 4) with those of $\mathrm{MgO}$ (Figure 1) reveals that the latter shows much more fine structure, indicating larger ordering and a more crystalline phase. The MgO-like phase formed after heating the HT at $725 \mathrm{~K}$ can be completely reversed into a HT structure, restoring the layered structure completely on the length-scale of the XAS, that is about $15 \AA$ around the absorber atom. This implies that separation of a $\mathrm{Mg}$ and an $\mathrm{Al}$ phase does not occur and, hence large crystalline $\mathrm{Mg}$ oxide or $\mathrm{Al}$ oxide phases are not expected.

\section{Conclusion}

$\mathrm{Mg}$ and $\mathrm{Al} \mathrm{K}$-edge spectroscopy is a unique tool for monitoring the changes in $\mathrm{Al}$ and $\mathrm{Mg}$ coordinations as a function of (calcination) temperature in HT-like compounds. The in situ and ex situ experiments show clear differences. This proves the importance of application of true in situ techniques when structural changes during the activation of a catalyst are investigated.

The structure of $\mathrm{HT}$ is very flexible. The $\mathrm{Al}$ and $\mathrm{Mg}$ coordinations can change depending on the conditions. At $425 \mathrm{~K}$, the coordination of some of the octahedrally coordinated $\mathrm{Al}$ centers becomes less through a reversible $\mathrm{Al}-\mathrm{OH}$ bond breakage. At temperatures higher than $475 \mathrm{~K}$, dehydroxylation of the $\mathrm{Mg}$ and $\mathrm{Al}$ cations in the cation layer occurs. This is a continuous process at increasing temperatures. The $\mathrm{Mg}$ coordination starts changing at temperatures above $475 \mathrm{~K}$ and formation of an MgO-like phase occurs. XAFS analysis indicates a $\mathrm{MgO}$-like structure after calcination at $725 \mathrm{~K}$ and the presence of a mixed tetrahedral-octahedral Al phase. The HT layered structure is completely restored after rehydration at room temperature and within the length-scale of XAS (ca. $15 \AA$ ) the obtained structures are identical to the as-synthesized material.

\section{Experimental Section}

\begin{abstract}
Sample preparation
An aqueous solution $(45 \mathrm{~mL})$ of $\mathrm{Mg}\left(\mathrm{NO}_{3}\right)_{2} \cdot 6 \mathrm{H}_{2} \mathrm{O}$ (0.1 mol, P.A. Acros) and $\mathrm{Al}\left(\mathrm{NO}_{3}\right)_{3} \cdot 9 \mathrm{H}_{2} \mathrm{O}(0.05 \mathrm{~mol}$, Z.A. Merck $)$ was added in one portion to a second solution $(70 \mathrm{~mL})$ containing $\mathrm{NaOH}(0.35 \mathrm{~mol})$ and $\mathrm{Na}_{2} \mathrm{CO}_{3}$ $(0.09 \mathrm{~mol})$ at $333 \mathrm{~K}$. The mixture was maintained at this temperature for $24 \mathrm{~h}$ under vigorous stirring, after which the white precipitate was filtered off and washed several times. The HT was dried for $24 \mathrm{~h}$ at $393 \mathrm{~K}$. This is denoted as the as-synthesized HT (HTa.s.). ICP analysis revealed a $\mathrm{Mg} / \mathrm{Al}$ ratio of $2 . \mathrm{MgO}$ was obtained by heating $\left(\mathrm{MgCO}_{3}\right)_{4} \cdot \mathrm{Mg}(\mathrm{OH})_{2} \cdot 5 \mathrm{H}_{2} \mathrm{O}$ (Sigma) under a flow of dry nitrogen to above $825 \mathrm{~K}$. The sample was cooled down under a flow of nitrogen to prevent the formation of hydroxides. $\mathrm{Mg}(\mathrm{OH})_{2}$ was prepared by dispersing $\mathrm{MgO}$ into decarbonated
\end{abstract}


water. These compounds were checked for crystallinity and structure by XRD.

$\mathrm{MgO}$ has a rock salt crystal structure in which the $\mathrm{Mg}$ is octahedrally coordinated. $\mathrm{MgAl}_{2} \mathrm{O}_{4}$ is a normal spinel structure, in which $\mathrm{Mg}$ occupies tetrahedral sites and $\mathrm{Al}$ octahedral sites in close-packed oxygen layers. $\mathrm{Mg}(\mathrm{OH})_{2}$ has the brucite structure, in which magnesium hydroxide octahedrons link to form infinite sheets. Hence, in $\mathrm{MgO}$ and $\mathrm{Mg}(\mathrm{OH})_{2}$, $\mathrm{Mg}$ is octahedrally coordinated, whereas in the normal spinel, $\mathrm{MgAl}_{2} \mathrm{O}_{4}$, it is tetrahedrally coordinated.

\section{Sample treatments}

HTex' $\boldsymbol{T}^{\prime}$ samples: Before measurement, the hydrotalcite was calcined to various temperatures in the laboratory under a nitrogen flow at heating rates of $10 \mathrm{~K} \mathrm{~min}^{-1}$. These samples are called $\mathrm{HTex}$ ' $T$ ', where ' $T$ ' represents the maximum calcination temperature. For example, HTex475 is HTa.s. heated in nitrogen at $10 \mathrm{~K} \mathrm{~min}^{-1}$ to $475 \mathrm{~K}$ and maintained at that temperature for $8 \mathrm{~h}$. The nitrogen flow was maintained during cooling down of the sample and the samples were stored under nitrogen. A batch of the sample calcined at $725 \mathrm{~K}$ (HTex725) was rehydrated at $303 \mathrm{~K}$ by use of a water-saturated nitrogen flow of $100 \mathrm{~mL} \mathrm{~min}^{-1}$ for at least $6 \mathrm{~h}$. This sample is referred to as HTex725r.h. XRD and $\mathrm{N}_{2}$ and $\mathrm{CO}_{2}$ sorption experiments on some of these samples have been published elsewhere. ${ }^{[3]}$ The HTex' $T^{\prime}$ samples were measured at room temperature.

HT' $^{\prime} \boldsymbol{T}^{\prime}$ samples: HTa.s. was measured in situ at the $\mathrm{Mg}$ and $\mathrm{Al} \mathrm{K}$-edges. Heating rate was $10 \mathrm{~K} \mathrm{~min}^{-1}$ under a flow of dry helium. These samples are called $\mathrm{HT}^{\prime} T^{\prime}$, where ' $T$ ' represents the temperature at which the measurement took place, hence HT425 is measured at $425 \mathrm{~K}$ under a flow of dry helium.

\section{XAFS measurements}

XAFS measurements were performed at beamline 3.4 at the SRS, Daresbury (UK). The in situ low-energy X-ray absorption fine structure (ILEXAFS) set-up ${ }^{[10,11]}$ were used. Both electron yield (measuring drain current) and fluorescence yield (using a gas proportional counter) were used as detection of the XAS signal, yielding very similar results. The intensity of the initial X-ray beam is determined by measuring the drain current of either a $\mathrm{Au}$ or a $\mathrm{Cu}$ mesh with a thickness of less than $3 \mu \mathrm{m}$.

$\mathrm{YB}_{66}$ crystals were used as monochromator crystals, allowing the measurement of both the $\mathrm{Al} \mathrm{K}$-edge near edge and the EXAFS. Using these crystals, the energy range at the $\mathrm{Mg} \mathrm{K}$-edge is limited to the near edge, due to higher order effects. Higher harmonics were removed by detuning the crystals (rocking of the Bragg peak) so the intensity was reduced to about $50 \%$ of the maximum intensity.

XANES analysis: The electron yield spectra were pre-edge and background subtracted and normalized after averaging three scans. The normalization was performed by dividing the pre-edge subtracted spectrum by the intensity of the post-edge background at $50 \mathrm{eV}$ above the edge. As the energy range above the $\mathrm{Mg} \mathrm{K}$ edge is limited, due to the used monochromator $\mathrm{YB}_{66}$ crystals, the spectra were post-edge, background fitted over the maximum data range available (ca. $60 \mathrm{eV}$ above the edge).

EXAFS analysis: The fluorescence data (average of three scans) were used to generate the EXAFS function. The background was subtracted using cubic spline routines. ${ }^{[25,26]}$ Reference phase shifts and back-scatterings amplitude functions of the $\mathrm{Al}-\mathrm{O}$ absorber back-scatterer pair were determined for $\alpha-\mathrm{AlPO}_{4}$ (The procedure followed has been described in detail elsewhere). ${ }^{[28]}$ The spectra were fitted in $R$ space, from $1<R<2 \AA$ after Fourier transform of $2<k<8 . k^{0}, k^{1}$, and $k^{3}$ weighting of the spectra was performed and the best fit was obtained in all dimensions.

\section{Acknowledgement}

Ad van der Eerden and Dr. Andy Smith are gratefully acknowledged for their help with the XAS experiments at beamline 3.4 at the SRS Daresbury (UK).

[1] F. Cavani, F. Trifiro, A. Vaccari, Catal. Today 1991, 11, 173.

[2] K. Koteswara Rao, M. Gravelle, J. Valente, F. Figueras J. Catal. 1998, $173,115$.

[3] J. C. A. A. Roelofs, A. J. van Dillen,, and K. P. de Jong, Catal. Today 2000, 60(3-4), 297.

[4] C. Noda, Alt, G. P. Werneck, R. M. Henriques, C. A., Monteiro, J. L. F. Braz, J. Chem. Eng. 1998, 15, 120.

[5] W. T. Reichle, S. Y. Kang, D. S. Everhardt, J. Catal. 1986, 101, 352.

[6] E. Kanezaki Inorg.Chem. 1998, 37, 2588.

[7] K. J. D. MacKenzie, R. H. Meinhold, B. L. Sherriff, Z. Xu, J. Mater. Chem. 1993, 3(12), 1263.

[8] M. J. Hudson, S. Carlino, D. C. Apperley, J. Mater. Chem. 1995, 5(2), 323.

[9] T. Hibino, Tsunashima, A. Chem. Mater. 1998, 10, 4055.

[10] J. A. Van Bokhoven, A. M. J. van der Eerden, A. D. Smith, D. C. Koningsberger, J. Synchrotron Rad. 1999, 6, 201.

[11] A. M. J. Van der Eerden, J. A van Bokhoven, A. D. Smith, and D. C. Koningsberger, Rev. Sci. Instr. 2000, 71(9), 1.

[12] J. A. van Bokhoven, H. Sambe, D. E. Ramaker, D. C. Koningsberger, J. Phys. Chem. B 1999, 103(36), 7557.

[13] O. Bigey, C. Depège, A. de Roy, J. P. Besse, J. Phys. IV France 1997, 7 Colloque C2, Supplément au Journal de Physique d'avril 1997, C2 949-951.

[14] H.Yoshida, T. Yoshida, T. Tanaka, T. Funabiki, S. Yoshida, T. Abe, K. Kimura, T. Hattori, J. Phys. IV France 1997, 7, Colloque C2, Supplément au Journal de Physique d'avril 1997, C2-911-912.

[15] J. A. van Bokhoven, H. Sambe, D. C. Koningsberger, D. E. Ramaker, J. Phys. IV France, 1997, 7, Colloque C2, Supplément au Journal de Physique III d'Avril, 1997, C2 -835-840.

[16] G. A. Waychunas, G. E. Brown Jr., EXAFS and Near Edge Structures $I I I$, K. A. Hodgts, B. Hedman, J. E. Penner-Hahn, Springer, Berlin, 1984, p. 336.

[17] D. Li, G. M. Bancroft, M. E. Fleet, X. H. Feng, Y. Pan American Miner. 1995, 80, 432.

[18] D. A. McKeown., G. A. Waychunas, G. E. Brown Jr. J. Non-Cryst. Solids 1985, 74, 349.

[19] D. Cabaret, P. Sainctavit, P. Ildefonse, A. -M. Flank J. Phys. : Condens. Matter. 1996, 8, 3691.

[20] C. S. Doyle, S. J. Traina, H. Ruppert, T. Kendelewicz, J. J. Rehr, G. E. Brown, Jr. J. Synchrotron Rad. 1999, 6, 621.

[21] R. W. G. Wyckoff. Crystal Structure, 2nd ed, Wiley, New York, 1963, p. 7.

[22] R. Allmann, H. P. H. Jepsen, Jhb Miner Mh 1969, 12, 465.

[23] F. Von Freund Ber. Dtsch. Keram. Ges. 1965, 42, 23.

[24] L. Pesic, S. Salipurovic, V. Markovic, D. Vucelic, W. Kagunya, W. Jones, J. Mater. Chem. 1992, 2(10), 1069.

[25] F. Rey, V. Fornes, J. M. Rojo, J. Chem. Soc. Faraday Trans. 1992, 88, 2233.

[26] J. W. Cook Jr., D. E. Sayers, J. Appl. Phys. 1981, 52, 5024.

[27] J. B. A. D. van Zon, D. C. Koningsberger, H. F. van't Blik, D. E. Sayers, J. Chem. Phys. 1985, 82, 5742.

[28] D. C. Koningsberger, J. T. Miller. Catal. Lett. 1994, 29, 77. 